\title{
Key rate and loan market in Russia
}

\author{
S. M. Borodachev \\ Graduate School of Economics and Management, Ural Federal University named after the First President of Russia \\ B. N. Yeltsin, Mira St 19, 620002, Ekaterinburg, Russia. \\ e-mail:s.m.borodachev@gmail.com
}

The paper proposes a mechanism for the impact of changes in the key rate on the volume of newly issued loans. The volume depends on the price (interest rates on loans), and the price depends on the key rate and the actual consumption of loans in the previous period (generalized cobweb cycle). The model was estimated by a Kalman filter, adequacy was confirmed by simulation. It is possible to forecast the average rate on loans for a month in advance according to the information published by the Central Bank of the Russian Federation (CB). By playing various scenarios for changing the key rate, it was found that in quiet periods of economic development, the usual laws of supply and demand operate in the loan market and by raising the key rate, you can reduce inflation. In the turbulent (overheated) state of the economy, an increase in the key rate can, on the contrary, provoke an increase in the issuance of loans and unconventional manipulations with the key rate are required.

\section{Keywords: cobweb cycle, money creation, inflation, Kalman filter, scenarios}

\section{INTRODUCTION}

The picture of the loan market in Russia. As follows from the review of credit institutions in [1], the liabilities of banks on ruble deposits to non-financial organizations and the households (mainly arising from the issuance of loans and borrowings) amount to $\sim 46$ trillion rubles on 01.01.21. At the same time, new loans for $\sim 4$ trillion $\mathrm{P}$ are issued monthly (the old ones are being repaid in the meantime). The increase in the issuance of new loans according to various estimates (see [2], [3]) is from 160 to 300 billion P on average per month. This growth in the money supply is causing inflation, which is containing mainly by regulating the key rate at which banks borrow from the CB.

The objective of this work: modeling the mechanism of the impact of changes in the key rate on the volume of loans issued, playing out possible scenarios. Basic assumptions: consumption of loans depends on their prices, loans are supplied to the market at a price determined, mainly, by the key rate of the $\mathrm{CB}$ and real demand.

\section{MODEL AND DATA}

Observed system's output at points in time (the beginning of the subsequent months) $t=1,2, \ldots, T=31$ (from 01.02.2019 to 01.08.2021) are

$$
y^{t}=\left(\begin{array}{c}
p f^{t} \\
l f^{t-1}
\end{array}\right),
$$

where $p f^{t}$ - reported weighted average interest rate on loans (up to 1 year) provided by credit institutions to non-financial organizations in rubles per month starting at time $t$ [4], and $l f^{t}$ - reported volume of loans provided to legal entities residents and individual entrepreneurs in rubles (in the whole of the Russian Federation) per month starting at time $t$ [2]. 
Let us introduce the values: $p^{t}$ - the true weighted average interest rate on loans, $l^{t}$ - the true volume of loans, $p k^{t}-$ the key rate of the CB [5]. The values $p f^{t}, p^{t}, p k^{t}$ will be measured in units $P k^{1}=7.75 \%$ - the key rate at the base moment $t=1(02 / 01 / 2019), l f^{t}$ and $l^{t}$ in units $L f^{1}=3.327$ trillion $\mathrm{P}$ - the volume at the same base moment.

We will assume that the dynamics of the loan market is determined by the dependence of the demanded volume (consumption) of loans on the interest rate

$$
l^{t}=\beta_{0}-\beta_{1}\left(p^{t}+\frac{p k^{t+1}-p k^{t}}{2}\right)+\delta_{0}^{t},
$$

and the price (interest rate) of the offer of loans for the next month depends on the real volume of loans consumption in the current month

$$
p^{t+1}=p k^{t+1}+\beta_{2}+\beta_{3} l^{t}+\delta_{1}^{t} .
$$

This leads to the well-known cobweb "pork supply" cycle, see Fig. 2. Equation (3) uses the average rate (at the beginning of the month $p^{t}$, at the end $p^{t}+\left(p k^{t+1}-p k^{t}\right)$. All $\beta$ for traditional market considerations are expected $\geq 0, \beta_{2}$ reflects the banks' margin when borrowing from the $\mathrm{CB}$ at the rate $p k^{t+1} . \delta_{0}^{t}$ and $\delta_{1}^{t}$ - random errors.

Substitute (1) into (2), introduce the state vector of the system $x^{t}=\left(\begin{array}{lll}1 & p^{t} & l^{t-1}\end{array}\right)^{T}$, and control vector

$$
u^{t}=\left(\begin{array}{ll}
p k^{t+1} & p k^{t}
\end{array}\right)^{T}
$$

Then the model of the system in the state space has a form

$$
\begin{aligned}
& x^{t+1}=F^{t} x^{t}+G^{t} u^{t}+w^{t}, \\
& y^{t}=H^{t} x^{t}+v^{t}
\end{aligned}
$$

where the operator of evolution $F^{t}=\left(\begin{array}{ccc}1 & 0 & 0 \\ \beta_{0} \beta_{3}+\beta_{2} & -\beta_{1} \beta_{3} & 0 \\ \beta_{0} & -\beta_{1} & 0\end{array}\right)$, control $G^{t}=\left(\begin{array}{cc}0 & 0 \\ 1-\frac{\beta_{1} \beta_{3}}{2} & \frac{\beta_{1} \beta_{3}}{2} \\ -\frac{\beta_{1}}{2} & \frac{\beta_{1}}{2}\end{array}\right)$, and observation $H^{t}=\left(\begin{array}{lll}0 & 1 & 0 \\ 0 & 0 & 1\end{array}\right)$

\section{KALMAN FILTER AND INTERPRETATION OF CALCULATION RESULTS}

We choose the estimate of the initial state at time $T l-1 \hat{x}^{T l-1 \mid T l-1}$ as $\left(\begin{array}{lll}1 & p f^{T l-1} l f^{T l-2}\end{array}\right)^{T}$, and the covariance matrix of this estimate as $\sigma_{P}^{2}\left(\begin{array}{ccc}0 & 0 & 0 \\ 0 & 1 & 0 \\ 0 & 0 & 1\end{array}\right)$. We take the covariance matrix of the observation error vector $v^{t}$ equal to $\sigma v^{2}\left(\begin{array}{ll}1 & 0 \\ 0 & 1\end{array}\right)$, and of $w^{t} \sigma \delta^{2}\left(\begin{array}{ccc}0 & 0 & 0 \\ 0 & 1 & -1 \\ 0 & -1 & 1\end{array}\right)$. The latter means the anticorrelation of errors in (7) and (8), which gave a better description than their correlation or independence.

The estimation of the model parameters vector 


$$
\theta=\left(\sigma v \sigma \delta \sigma_{P} \beta\right)^{T},
$$

was carried out by minimizing the mean square weighted sum of errors in predicting rate and volume.

$$
\begin{gathered}
\operatorname{RMSE}(\theta)=\sqrt{\frac{1}{T-1} \sum_{t=T l}^{T_{u}}\left\{5\left[\left(y^{t}\right)_{0}-\left(\hat{y}^{t t-1}\right)_{0}\right]^{2}+\left[\left(y^{t}\right)_{1}-\left(\hat{y}^{t t-1}\right)_{1}\right]^{2}\right\},} \\
\hat{\theta}_{R M S E}=\underset{\hat{\theta}}{\arg \min } \operatorname{RMSE}(\hat{\theta}) .
\end{gathered}
$$

Here, $T l$ and $T u$ are the lower and upper boundaries of the time period under consideration., $\hat{y}^{t t-1}$ is the forecast for information at point $t$ - 1 (i.e., up to the value $y^{t-1}$ and $u^{t-1}$ ) of the output vector at the next point. Weight 5 provides an emphasis on interest rate prediction. Calculations done at PTC ${ }^{\circledR}$ Mathcad Prime ${ }^{\circledR}$.

Let us consider separately two periods of different economic conditions.

1. From $T l=2(03.2019)$ to $T u=22(11.2020)$. During this period (relatively favorable, quiet), loan rates decreased (together with the key rate), then remained unchanged. The volume of new loans grew moderately (see Fig. 1). The minimum RMSE was found to be 0.221 (for a random walk model (when the forecast is the previous value) RMSERW $=0.311)$.

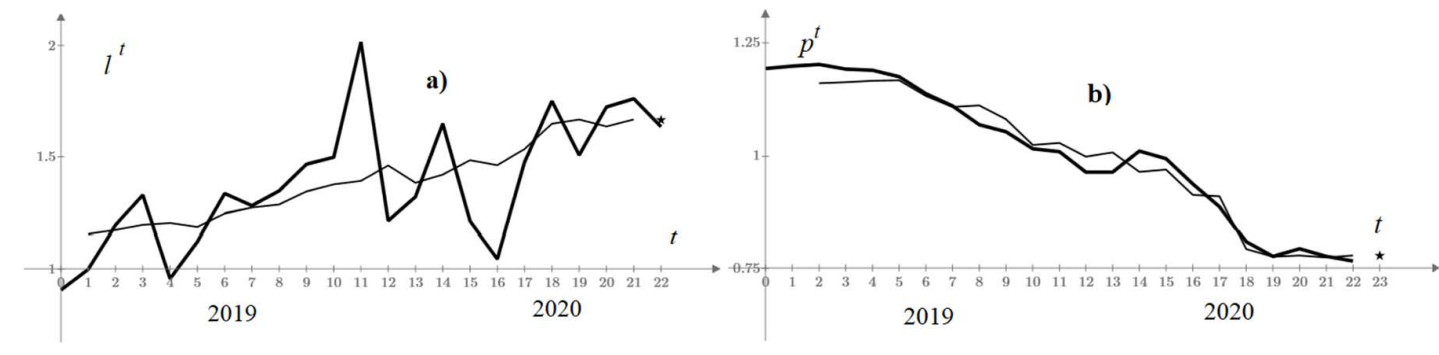

Figure 1. Monthly data from 01.2019 to 12.2020 . Observed financial indicators (solid curves), adjusted forecasts according to the information a month ago (thin solid curves - training), forecast according to the estimated model (asterisk). a) the volume of new loans, b) interest rates on loans.

The volume of loans in November $2020\left(l f^{22}\right)$ from the original data was not used in the calculations and the forecast (asterisk) can be compared with it. The found forecast value of the rate on loans that will be issued in December 2020 ( $t$ $=23$ ) have used the key rate for December 1 and can be checked only in a month.

Estimated parameters in (9):

$\beta_{0}=2.576$, i.e., the potential capacity of the loan market (at a zero interest rate) is 8.6 trillion P $(=2.576 * 3.327)$ new loans per month.

$\beta_{1}=1.184$ gives an average coefficient of elasticity of loan volumes at the interest rate (relative) equal to $-0.83 \%$. In other words, if absolute interest rates increase from the usual $8 \%$ to $9 \%$, the volume of new loans will decrease by $10 \%$. $3 \%$. This will lead to a decrease in M2 money supply by $\sim 10 \%$ per year, which will compensate its usual growth by about the same amount. Thus, in this case, we can expect about zero inflation for the year.

$\beta_{2}=0.005$ is the minimum bank margin in relative units. In absolute terms, it is $0.04 \%\left(0.005^{*} 7.75\right)$. That is, the potential rate on loans at very small total volume tends to the key rate $+0.04 \%$.

$\beta_{3}=0.135$ gives an average coefficient of elasticity of the new interest rate on the volume of loans issued (relative) equal to $0.19 \%$. This means a weak dependence of the loans supply price on demanded volume and its rigid binding to the key rate of the $\mathrm{CB}$ (with an average actual volume of loans, the offer price is equal to the key rate $+1.53 \%$ ). That is, by changing the key rate, it is possible to regulate the loan rate, the volume of loans, the money supply and inflation. 
With these parameters, demand and supply lines (between which a cobweb cycle develops) depicted in Fig. 2 for the moment $t=22(01.11 .2020)$.

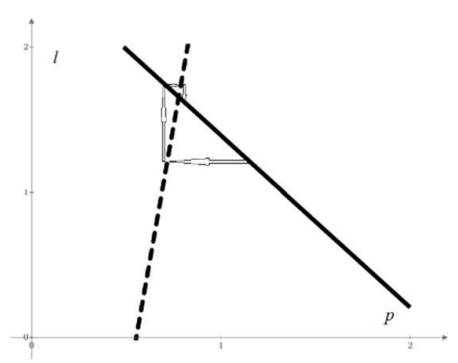

Figure 2. The volume of demand from the price (continuous straight line), the supply price from demand (dotted line).

2. From $T l=22(11.2020)$ to $T u=31$ (08.2021). During this period (unfavorable, turbulent), the volume of loans issued grew, the key rate was raised, loan rates increased. Large volumes of loans issued in July and August 2021 can be explained by the rush expectations of an increase in rates in the near future after an increase in the key rate (see Fig. 3). The minimum RMSE is 0.235 (RMSERW $=0.452)$.
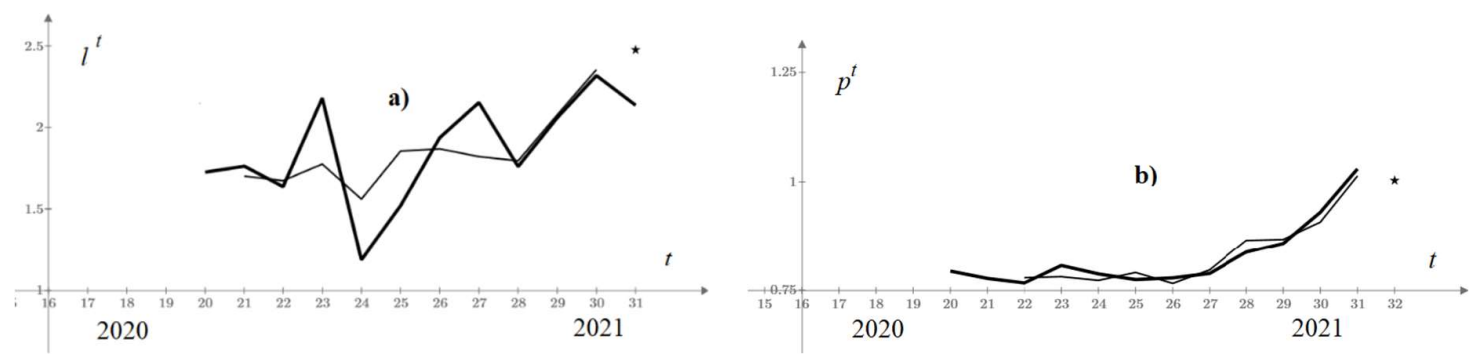

Figure 3. Monthly data from 09.2020 to 09.2021. Observed financial indicators (solid curves), forecasts adjusted to them according to information a month ago (thin solid curves - training), forecast for the evaluated model (asterisk). a) volumes of new loans, b) interest rates on loans.

$l f^{31}$ from the original data was not used in the calculations and you can compare the forecast (asterisk) with it. The resulting forecast value of the rate on loans that will be issued in September $2021(t=32)$ used the key rate for September 1 , and it can be checked only in a month.

Estimated parameters in (9):

$\beta_{0}=-0.706 . \beta_{1}=-3.097$ gives an average coefficient of elasticity of loan volumes at the interest rate (relative) equal to $+1.37 \%$. In other words, with an increase in interest rates, the volume of new loans will increase!

$\beta_{2}=0.374$. that is, the potential rate on loans at very small total volume tends to the key rate $+2.8 \%$.

$\beta_{3}=-0.084$ gives the average elasticity coefficient of the new interest rate on the volume of loans issued (relative) equal to $-0.19 \%$. This means weak (inverse!) dependence of the supply price on demand and its rigid binding to the key rate of the $\mathrm{CB}$ (with the average actual volume of loans, the offer price is equal to the key rate $+1.66 \%$ ).

With these parameters, demand and supply lines practically swap places in Fig. 2, but the convergence of the cobweb cycle (now counterclockwise) is preserved. 


\section{SIMULATION AND SCENARIOS}

To verify the adequacy of the system model, it is necessary to compare its functioning with the estimated parameters (simulation) with the behavior of the real system. To do this, you can use the equations of dynamics (5) and (6) without noise elements [3]. Or, equivalently, use these parameters to build the transfer matrix of the system $W(z)=H(z I-F)^{-1} G$ and, after the reverse z-transformation, get the output of the system [6]. We start with the same initial vector of state, controls - real (4) . In the same way, it is possible, by setting different types of control outside the sample, to play the system development scenarios. We will do this separately for the above-mentioned time periods.

For a quiet period, see Fig. 4.

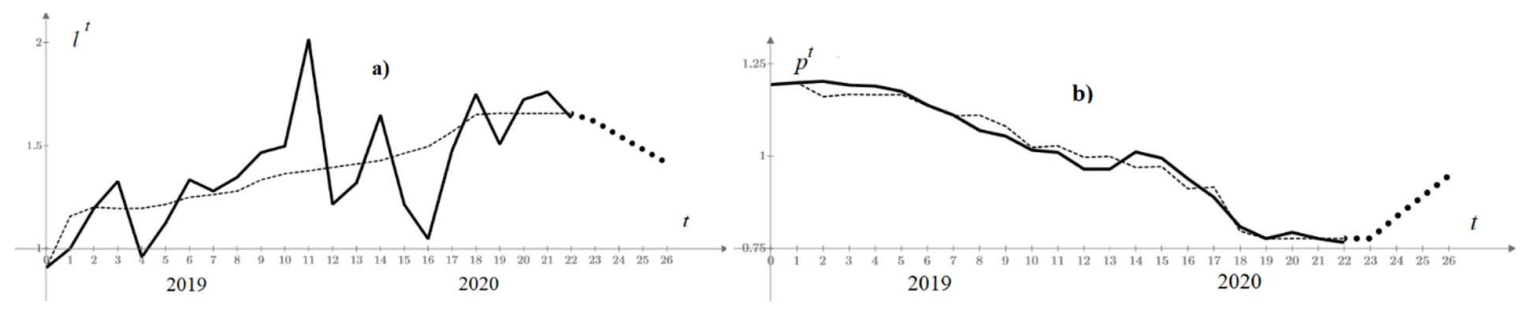

Figure 4. Comparison of real (solid curves) and simulated (dashed curves) financial indicators. Scenario with constant increase (after $t=23$ ) of the key rate by $0.5 \%$ per month (point curves). a) volumes of new loans, b) interest rates on loans.

Here, a scenario with a $0.5 \%$ decrease in the key rate per month leads to an expected decrease in rates and an increase in loans.

For a turbulent period, see Fig. 5.
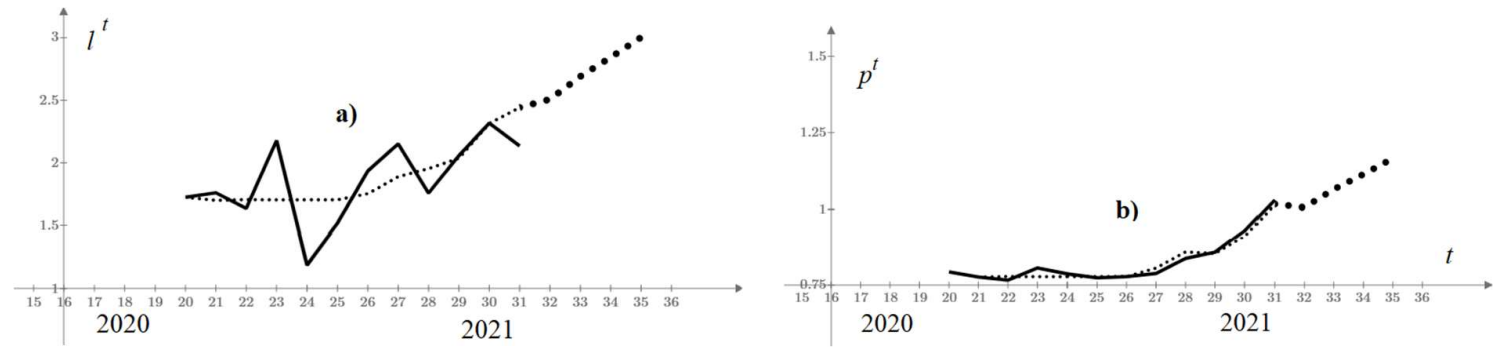

Figure 5. Comparison of real (solid curves) and simulated (dashed curves) financial indicators. A scenario with a constant increase (after $t=32$ ) of the key rate by $0.5 \%$ per month (point curves). a) volumes of new loans, $\mathrm{b}$ ) interest rates on loans.

Here there is an abnormal increase in the volume of new loans with an increase in rates, so a careless increase in the key rate can provoke a sharp increase in the money supply (at least in the short term) and a decrease in the key rate, on the contrary, would calm the market and reduce the volumes!

Interestingly, if periodically raise the key rate by $1 \%$, and, in a month, lower by $1 \%$, then the interest rates on loans will fluctuate, but the volumes will be almost constant (both in calm and turbulent periods).

In general, a good coincidence of solid and dotted curves (excluding random peaks and dips) in Fig. 4, 5 allows us to conclude about the adequacy of the proposed model to the real system. 


\section{CONCLUSION}

The paper proposes a model of the loan market in Russia of the "pork supply" cycle type, estimates the market parameters: potential market capacity, bank margin, elasticity coefficients. In particular, a weak dependence of the price of loans on their volume was found.

It is shown that the model, due to the diversity and volatility of economic conditions, should be based on a recent piece of data (several months) and develop forecasts and scenario recommendations for the next $1-2$ months.

\section{REFERENCES}

1. Bank of Russia Statistical Bulletin № 8 (339), “Business news agency PRIME”, 2021.

2. http://www.cbr.ru/vfs/statistics/BankSector/Loans_to_corporations/01_01_A_New_loans_corp_by_activity.xlsx

3. Borodachev, S. Toward the Modeling of Russia's Monetary System. Preprints (www.preprints.org) 2020030086, 2020 (doi: 10.20944/preprints202003.0086.v2).

4. http://www.cbr.ru/vfs/statistics/pdko/int_rat/loans_nonfin.xlsx

5. http://www.cbr.ru/hd_base/keyrate/\#highlight=\%D0\%BA $\%$ D0 $\%$ BB $\% \mathrm{D} 1 \% 8 \mathrm{E} \% \mathrm{D} 1 \% 87 \% \mathrm{D} 0 \% \mathrm{~B} 5 \% \mathrm{D} 0 \% \mathrm{~B} 2 \% \mathrm{D} 0 \%$ B0\%D1\%8F\%7C\%D1\%81\%D1\%82\%D0\%B0\%D0\%B2\%D0\%BA\%D0\%B0

6. Borodachev, S. M. Physics - Economics interdisciplinary analogies in modelling of Russian financial system. CEUR Workshop Proceedings, 2562, p. 113-120, 2020 (http://ceur-ws.org/Vol-2562/). 